\title{
Functional NMDA Receptors at Axonal Growth Cones of Young Hippocampal Neurons
}

\author{
Philip Y. Wang, ${ }^{1,2}$ Ronald S. Petralia, ${ }^{2}$ Ya-Xian Wang, ${ }^{2}$ Robert J. Wenthold,${ }^{\dagger \dagger}$ and Stephan D. Brenowitz ${ }^{1}$ \\ ${ }^{1}$ Section on Synaptic Transmission and ${ }^{2}$ Laboratory of Neurochemistry, National Institute on Deafness and Other Communication Disorders, National \\ Institutes of Health, Bethesda, Maryland 20892
}

\begin{abstract}
NMDA receptors (NMDARs) are critical to the development of the nervous system, although their roles at axonal growth cones are unclear. We examined NMDAR localization and function at axonal growth cones of young hippocampal neurons. Our immunocytochemical data showed that native and transfected NMDAR subunits are expressed in axons and growth cones of young (days in vitro 3-6) hippocampal rat neurons. Moreover, immunogold electron microscopy showed that NR1 is expressed in growth cones of postnatal day 2 rat hippocampus. Local application of NMDAR agonists to growth cones of voltage-clamped neurons evoked inward currents that were blocked by bath application of an NMDAR antagonist (DL-APV), indicating that these NMDARs are functional. In addition, calcium imaging experiments indicated that NMDARs present in growth cones mediate calcium influx. Calcium transients in growth cones persisted despite pharmacological blockade of voltage-sensitive calcium channels and depletion of intracellular calcium stores. Our findings reveal the presence of functional NMDARs in axons and growth cones of young neurons, suggesting a role for these receptors in axonal guidance and synapse formation during neuronal development.
\end{abstract}

\section{Introduction}

NMDA receptors (NMDARs) are ionotropic glutamate receptors that mediate key functions in the CNS, including synaptic plasticity, learning and memory, and neuronal development. NMDAR activation allows the influx of calcium ions, a critical second messenger that regulates numerous biological functions throughout neuronal development such as neurite outgrowth and axonal growth cone motility (Henley and Poo, 2004; Zheng and Poo, 2007). NMDAR activity promotes neuronal migration in embryonic mouse cortex and fine mapping of synaptic connectivity (Forrest et al., 1994; Behar et al., 1999). Studies in cerebellar granule cells demonstrated that NMDAR-mediated migration is calcium dependent (Komuro and Rakic, 1993; Kumada and Komuro, 2004) and may be directly influenced by subunit composition (Tárnok et al., 2008). Calcium influx through NMDARs has also been shown to stimulate neuritogenesis in developing neurons and to promote various aspects of neurite outgrowth (Pearce et al., 1987; Brewer and Cotman, 1989;

\footnotetext{
Received Oct. 27, 2010; revised March 29, 2011; accepted April 30, 2011

Author contributions: P.Y.W., R.S.P., R.J.W., and S.D.B. designed research; P.Y.W., R.S.P., Y.-X.W., and S.D.B. performed research; P.Y.W., R.S.P., R.J.W., and S.D.B. analyzed data; P.Y.W., R.S.P., R.J.W., and S.D.B. wrote the paper.

This work was supported by the NIDCD Intramural Research Program. We thank Drs. Katherine Roche, Jeff Diamond, Martin Horak, Elizabeth Webber, Catherine Croft Swanwick, Doris Wu, and members of the NIDCD Section on Synaptic Transmission and the Laboratory of Neurochemistry for critical reading of this manuscript. Thanks to Dr. Fang Hua for excellent technical assistance. Dr. Philip Wang was a PhD student in the NIH Graduate Partnerships Program with the University of Maryland, College Park, Neuroscience and Cognitive Sciences Program, during portions of this work. This manuscript is dedicated to the memory of our great friend and mentor, Dr. Robert J. Wenthold.

${ }^{\dagger}$ Deceased, October 30, 2009.

Correspondence should be addressed to Dr. Stephan D. Brenowitz, NIDCD/NIH, 50 South Drive, MSC 8027, Building 50, Room 4152, Bethesda, MD 20892-8027. E-mail: brenowitzs@nided.nih.gov.

DOI:10.1523/JNEUROSCI.5639-10.2011

Copyright $\odot 2011$ the authors $\quad 0270-6474 / 11 / 319289-09 \$ 15.00 / 0$
}

Rashid and Cambray-Deakin, 1992). In Xenopus spinal neuron cultures, NMDARs influence growth cone turning and filopodial asymmetry (Zheng et al., 1996). A more recent study suggests that NMDARs expressed at growth cones of dopaminergic nigrostriatal neurons promote axonal growth and growth cone splitting (Schmitz et al., 2009).

Attempts to study NMDAR localization within growth cones, however, have produced somewhat differing results (Ehlers et al., 1998; Herkert et al., 1998). For example, the obligatory NMDAR subunit NR1 has been shown to localize to axonal growth cones of young hippocampal neurons, and these receptors interact with neuronal intermediate filaments, implying direct functional connections to the cytoskeletal apparatus (Ehlers et al., 1998). However, others have described the enrichment of NR2B but not NR1 subunits at axonal growth cones (Herkert et al., 1998). This discrepancy could be attributable to difficulties in producing highly specific primary antibodies to NMDAR subunits. Here, using immunocytochemistry and immunogold EM, we demonstrate that NR1 subunits are present in axonal growth cones of days in vitro 3 (DIV3) to DIV6 hippocampal neurons in vitro and in vivo and that transfected NR2A and NR2B subunits also localize to the growth cones. More importantly, we demonstrate that these NMDARs are functional because local activation of NMDARs at growth cones mediates inward excitatory currents and elicits calcium influx. Furthermore, although NMDARs are present in axons and growth cones of young (DIV3-DIV6) hippocampal neurons, their expression at distal axons of mature (DIV16) neurons is greatly reduced, suggesting that NMDAR trafficking is developmentally regulated.

\section{Materials and Methods}

Primary hippocampal cultures. Embryonic day 18 (E18) primary hippocampal cultures were prepared as described previously (Wang et al., 
2008). Briefly, hippocampi from E18 rats of either sex were dissected, and cells were dissociated and plated onto coverslips at high density $(50,000 \mathrm{cells} / \mathrm{ml})$ for transfection or low density $(500-5000$ cells $/ \mathrm{ml})$ for electrophysiology and calcium imaging experiments. Growth cones were examined between DIV3 and DIV6. Beyond this age range, growth cones become increasingly difficult to find even in lowdensity cultures because isolated neurons form autapses. To minimize variability and contribution of somatic responses for electrophysiology and calcium imaging experiments, strict morphological and geometric criteria were used in the selection of neurons to analyze. Only isolated neurons (with no visible contacts with adjacent cells) that had morphologically distinct axonal growth cones positioned downstream of the perfusion flow, relative to the cell body, were chosen for examination.

Transfections and immunocytochemistry. Transfections and immunocytochemistry were performed as described previously (Wang et al., 2008). Briefly, neurons were fixed with $4 \%$ paraformaldehyde (PFA), washed with PBS, and permeabilized with $0.25 \%$ Triton X-100/ PBS. Neurons were then blocked with $10 \%$ normal goat serum (NGS)/PBS/0.1\% Triton $\mathrm{X}-100$ for $1 \mathrm{~h}$ and then incubated with primary antibodies at room temperature in 3\% NGS/ PBS/0.1\% Triton X-100 for $1 \mathrm{~h}$. Neurons were washed and incubated with Alexa Fluor 488 or 555 secondary antibodies (Invitrogen) for 30 min and washed and mounted on slides using Prolong Antifade Gold (Invitrogen). For surface staining experiments, live neurons were incubated with primary antibodies for $30 \mathrm{~min}$ at $4^{\circ} \mathrm{C}$, fixed with $4 \%$ PFA for $20 \mathrm{~min}$, blocked with $10 \% \mathrm{NGS} / \mathrm{PBS}$, and incubated with secondary antibodies for $30 \mathrm{~min}$. Neurons were transfected with cDNA constructs at various ages in culture (DIV4-DIV14) using the calcium phosphate method. Plasmids encoding GFP-NR2A, GFP-NR2B, and YFP-NR1-1 were generously provided by Dr. Stefano Vicini (Georgetown University School of Medicine, Washington, DC). Surface or permeabilized immunocytochemistry was performed $48 \mathrm{~h}$ after transfection and visualized using a Nikon E1000M microscope equipped with a CCD camera using a Plan Apo $60 \times(1.4 \mathrm{NA})$ or Plan Fluor $40 \times(1.3 \mathrm{NA})$ oil-immersion objective or a Carl Zeiss LSM 710 laser scanning confocal microscope with a $63 \times(1.4 \mathrm{NA})$ oil-immersion Plan Apo objective. GFP polyclonal antibodies were purchased from Millipore and used at 1:2000 dilution for surface and permeabilized immunocytochemistry. The NR1 rabbit monoclonal antibody was from Millipore, based on a 30 aa sequence in the NR1 C-terminal tail (amino acids 909-938: LQNQKDTVLPRRAIEREEGQLQLCSRHRES) and used at a 1:1:000 dilution for permeabilized immunocytochemistry. This sequence corresponds to four of the eight known NR1 splice variants (NR1-1a, NR1-1b, NR1-2a, and NR1-2b).

Electrophysiology. The extracellular recording solution contained 1.25 mм NaH ${ }_{2} \mathrm{PO} 4,150 \mathrm{~mm} \mathrm{NaCl}, 2.5 \mathrm{~mm} \mathrm{KCl}, 5$ mм HEPES, 10 mм glucose, $10 \mu \mathrm{M}$ D-serine, and $0.2 \mathrm{mM} \mathrm{CaCl}_{2}, \mathrm{pH}$ 7.3. Somatic whole-cell voltageclamp recordings were performed with borosilicate glass electrodes $(6-8$ $\mathrm{M} \Omega$ ) filled with a cesium-based internal solution containing the following (in mM): $130 \mathrm{CsMeSO}_{4}, 10$ HEPES, 5 EGTA, $1 \mathrm{MgCl}_{2}, 10$ tetraethylammonium-Cl, $2 \mathrm{Mg}$-ATP, $0.3 \mathrm{Na}-\mathrm{GTP}, 10$ phosphocreatine (Tris), and 2 QX-314. Whole-cell voltage-clamp recordings were ob-
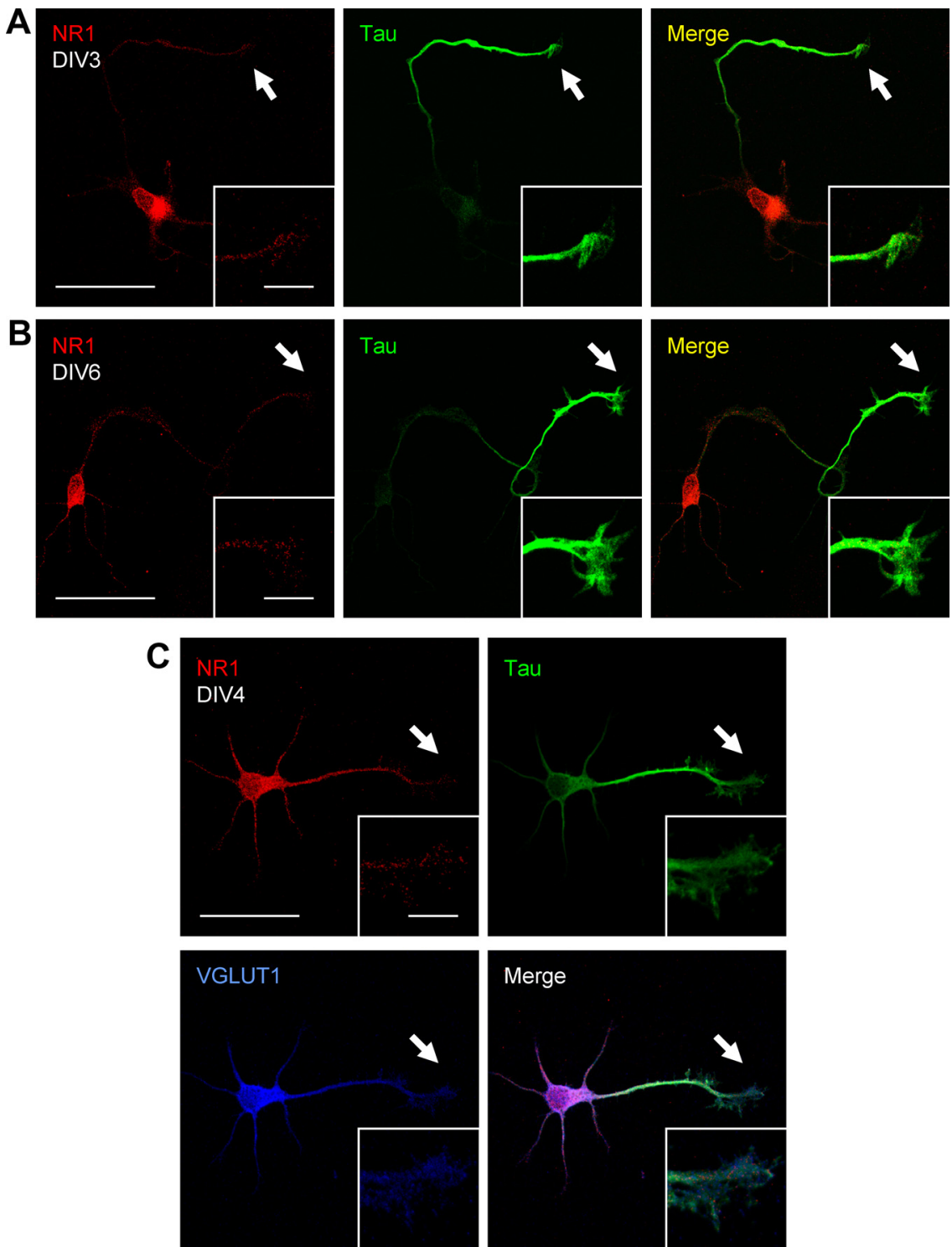

Figure 1. Endogenous NR1 is expressed in axons and growth cones of glutamatergic hippocampal neurons. A-C, DIV3-DIV6 rimary hippocampal cultures were coimmunostained for NR1 and the axonal protein tau. NR1 displays a punctate distribution glutamate transporter VGLUT1. Positive immunostaining of VGLUT1 was present in all neurons that displayed NR1 at axonal growth cones, indicating that these neurons are glutamatergic. Scale bars: large panels, $50 \mu \mathrm{m}$; insets, $10 \mu \mathrm{m}$.

tained from primary hippocampal neurons using a MultiClamp 700B (Molecular Devices) patch-clamp amplifier. Application of NMDA (200 $\mu \mathrm{M}$, in extracellular solution) was performed using a Picospritzer III (Parker Hannifen) pressure application system. Compounds were applied at 4-6 psi for $100 \mathrm{~ms}$. Cells were maintained at $-70 \mathrm{mV}$ for all conditions, and recordings were conducted at room temperature and analyzed using Igor Pro (Wavemetrics) software.

Pharmacology. The following pharmacological compounds were used, as described in text. In control electrophysiology and calcium imaging experiments, NMDARs were blocked by adding $100 \mu \mathrm{M}$ DL-APV (Tocris Bioscience) to the extracellular solution and introduced into the recording chamber by perfusion. Voltage-sensitive calcium channels (VSCCs) were blocked with $0.1 \mu \mathrm{M} \omega$-conotoxin MVIIC (Peptides International), $0.03 \mu \mathrm{M}$ SNX-482 (Peptides International), $20 \mu \mathrm{M}$ nimodipine (SigmaAldrich), and $10 \mu \mathrm{M}$ mibefredil (Sigma-Aldrich). These compounds block VSCCs $\mathrm{CaV}_{2.1 / 2.2}$ (P/Q- and N-type), $\mathrm{CaV}_{2.3}$ (R-type), $\mathrm{CaV}_{1.2 / 1.3}$ (L-type), and $\mathrm{CaV}_{3}$ (T-type) classes of VSCCs, respectively. Replenishment of intracellular calcium stores was blocked using $10 \mu \mathrm{M}$ cyclopia- 


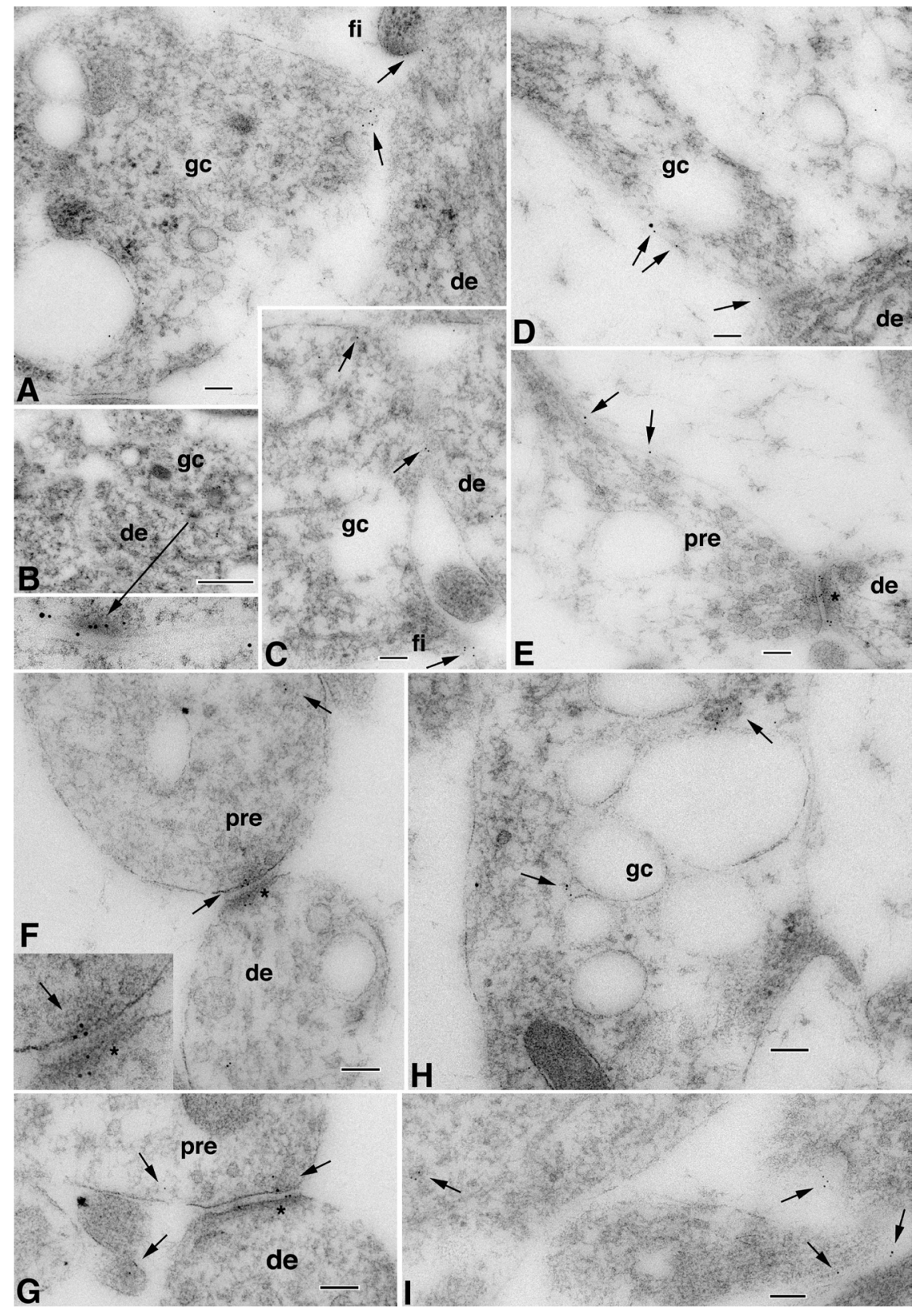

Figure 2. $\quad A-I$, Immunogold localization of NR1 at the surface $(5 \mathrm{~nm}$ gold particles indicated by arrows) of growth cones ( $\mathrm{gc}$ ) and subsequent early axon contacts in the $C A 1$ stratum radiatum $(B, D)$ or stratum oriens $(A, C, E-I)$ of the P2 hippocampus. Growth cones show characteristic collections of large and small endosomal vesicles. Some NR1 localizations are at contact points with dendrites (de). Some of the contacts are filopodial (fi). Note also the young but distinctive synaptic contacts in $\boldsymbol{D}$ and $E$; $D$ is an axonal growth cone with a few obscure synaptic vesicles near the presynaptic contact, whereas $\boldsymbol{E}$ shows a better developed synapse, including a presynaptic terminal (pre) with numerous, distinct synaptic vesicles and high gold labeling on the postsynaptic membrane (asterisk; a clathrin-coated vesicle is evident in the dendrite on the other side of the asterisk). The left part of the presynaptic terminal is expanded into a growth cone structure. $F$ and $G$ are similar to $\boldsymbol{D}$ and $\boldsymbol{E} . \boldsymbol{F}$ (and inset) is an early synaptic contact with just a few vesicles in the growth cone derived-presynaptic terminal, forming a synaptic junction with the postsynaptic membrane (asterisk; note the postsynaptic labeling for NR1) on a dendrite. Arrows indicate gold labeling in the terminal and on the presynaptic membrane. $G$ is a slightly more mature early synapse with more presynaptic vesicles; gold lines the postsynaptic membrane but also remains on the presynapticmembrane. Othergold particles are seen on the surface of an adjacent unidentified cell process. H shows gold labeling associated with endosomal structures (indicative of the active cyding of membrane to the surface) of part of a large growth cone. In I, NR1 (arrows) can be seen on the surface of and within various growing processes; the one on the right shows a cluster of vesicles and probably is part of an axonal growth cone. Scale bars: $A, C-I, 100 \mathrm{~nm} ; \boldsymbol{B}, 500 \mathrm{~nm}$; inset in $B, 100 \mathrm{~nm}$; inset in $F, 50 \mathrm{~nm}$.

zonic acid (CPA) (Tocris Bioscience). All reagents were dissolved in distilled water, except for nimodipine and CPA, which were dissolved in dimethylsulfoxide (DMSO).

Calcium imaging. Our standard extracellular solution was prepared with $1 \mathrm{~mm} \mathrm{CaCl}$ for these experiments. For AM-loading experiments,
DIV3-DIV6 primary hippocampal cultures were treated with the fluorescent calcium indicators Fluo-4 AM or Fluo-5F AM (Invitrogen). Fluo-4 AM or Fluo-5F AM ( $50 \mu \mathrm{g})$ was solubilized in $\mathrm{DMSO} / 0.8 \%$ pluronic $\mathrm{F}-127$ to create a $1 \mathrm{~mm}$ stock solution. The AM calcium indicator stock was applied to neurons in B27supplemented Neurobasal medium at a dilution of $1: 100$ and incubated at $37^{\circ} \mathrm{C}$ for 3 $\mathrm{min}$. Neurons were then washed with fresh culture media and incubated for $30 \mathrm{~min}$ at $37^{\circ} \mathrm{C}$. NMDA $(200 \mu \mathrm{M})$ was applied to axonal growth cones, and calcium transients were imaged using a QImaging Rolera Mgi EM CCD camera in conjunction with QCapture Pro 6 (QImaging) and IgorPro software (Wavemetrics). During control experiments performed to examine the spatial specificity of the local application system, we verified that NMDA application to the soma did not produce fluorescent calcium transients in the growth cone. As an additional measure to prevent diffusion of NMDA toward the cell body during experiments in which NMDA was locally applied to growth cones, neurons were selected with an orientation so that the flow of bath solution directed the NMDA solution away from the cell body. Images (100 ms exposures) were taken at $138 \mathrm{~ms}$ frame intervals, verified by output signals from the CCD camera. The exposure at the $0 \mathrm{~ms}$ time point in Figure 5 began at the onset of NMDA application. Calcium transients were quantified using MetaMorph version 7.0r3 (Molecular Devices). Regions of interest (ROIs) were selected to encompass the entire growth cone structure ( $\mathrm{P}$ and $\mathrm{C}$ areas), and background ROIs were selected within close proximity to the growth cone. $\Delta F / F$ measurements were performed using the following formula: $(F-$ $\left.F_{0}\right) / F_{0}$, where $F$ was the background subtracted fluorescent value, and $F_{0}$ was the average of the first five background subtracted frames (baseline levels). To examine the spatial distribution of calcium transients, $\Delta F / F$ images were generated using MetaMorph. All images were background subtracted, and the $F$ and $F_{0}$ images were generated through averaging pixel values of frames 10-14 (frames immediately after NMDA application) and frames 1-5 (baseline), respectively. The $\Delta F$ image $\left(F-F_{0}\right)$ was generated by subtracting the pixel intensity values of the $F$ and $F_{0}$ with a constant value of +1 , and the $\Delta F / F$ image was generated by the division function with a constant value of 100 in the numerator. Median filtering $(3 \times 3)$ was applied to the resulting $\Delta F / F$ image to eliminate background pixels.

Immunogold electron microscopy. Postembedding immunogold labeling was performed as described previously (Petralia and Wenthold, 1999; Petralia et al., 2010). Briefly, two postnatal day 2 (P2) rats were perfused with $4 \%$ paraformaldehyde plus $0.5 \%$ glutaraldehyde, and sections were cryoprotected and frozen in a Leica EM CPC and further processed and embedded in Lowicryl HM-20 resin using a Leica AFS freezesubstitution instrument. Thin sections were incubated in $0.1 \%$ sodium borohydride plus $50 \mathrm{~mm}$ glycine/Tris-buffered saline plus $0.1 \%$ Triton $\mathrm{X}-100$ (TBST), followed by $10 \%$ NGS in TBST, and primary antibody in 
$1 \%$ NGS/TBST overnight, and then immunogold labeling in $1 \%$ NGS in TBST plus $0.5 \%$ polyethylene glycol (20,000 molecular weight). Finally, sections were stained with uranyl acetate and lead citrate. Corresponding controls, lacking the primary antibody, showed only rare gold labeling. Images were stored in their original formats, and final images for figures were prepared in Adobe Photoshop. Brightness and contrast of images were minimally adjusted, evenly over the entire micrograph.

\section{Results}

NMDAR localization at growth cones of young glutamatergic

hippocampal neurons

To investigate the localization of NMDARs at growth cones, we performed immunocytochemistry for endogenous NR1 subunits in DIV3-DIV6 hippocampal neurons using a rabbit monoclonal antibody that recognizes a 30 aa segment in the distal $\mathrm{C}$ terminus of NR1, present in splice variants NR1-1a/b and NR1-2a/b (Petralia et al., 1994). To facilitate the identification of the axon and to visualize the morphology of the growth cone, neurons were coimmunostained for the axonal protein tau. Immunocytochemistry was performed at DIV3, DIV6, and DIV4 (Fig. $1 A-C$, respectively). The NR1 labeling revealed a punctate distribution throughout the soma, dendrites, axons, and growth cones. NR1 puncta were present at both the lamellipodia and filopodia of growth cones. Because this NR1 anti-

body was generated against the intracellular C terminus of NR1, it could not be used for surface immunolabeling of native receptors. To examine the question of neurotransmitter phenotype of these cultured hippocampal neurons, DIV4 neurons were triple labeled with antibodies to NR1, tau, and the vesicular glutamate transporter protein VGLUT1 or the vesicular GABA transporter protein VGAT. Positive immunostaining of VGLUT1 was present in all neurons that displayed NR1 at axonal growth cones (Fig. $1 C$ ), whereas VGAT staining was absent (data not shown), indicating that these neurons are glutamatergic. To investigate NR1 localization in vivo, we performed immunogold labeling in the hippocampus of $\mathrm{P} 2$ rats. At the ultrastructural level, growth cone profiles were identified typically as large, irregular structures containing characteristic collections of large and small endosomal vesicles (Rees et al., 1976; Petralia and Yao, 2007). Parts of filopodia sometimes could be seen along the edge. In some cases, the expansion of the structure from the parent neurite shaft was evident in the profile. Labeling for NR1 was seen on membranes and filopodial structures of growth cones and also was associated with the endosomal structures within growth cones, indicative of the active cycling of membrane to the surface (Kamiguchi and Lemmon, 2000; Washbourne et al., 2004). Some of the processes labeled for NR1 were definitive axonal growth cones that appear to be in the process of forming early presynaptic contacts with dendrites (Fig. 2).

To investigate the presence of NR2 subunits at axonal growth cones, GFP-NR2A or GFP-NR2B cDNA constructs were cotransfected with Discosoma sp. red fluorescent protein

\section{B}
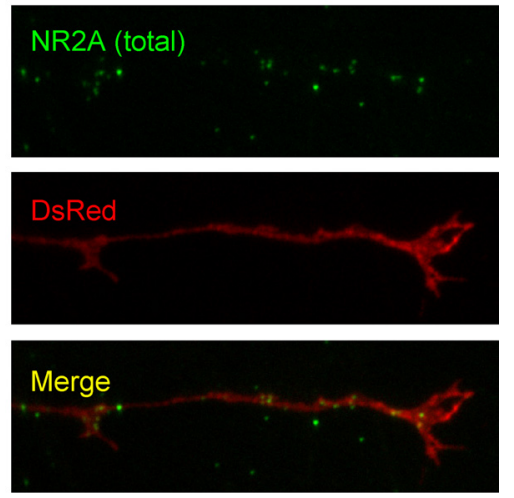

D
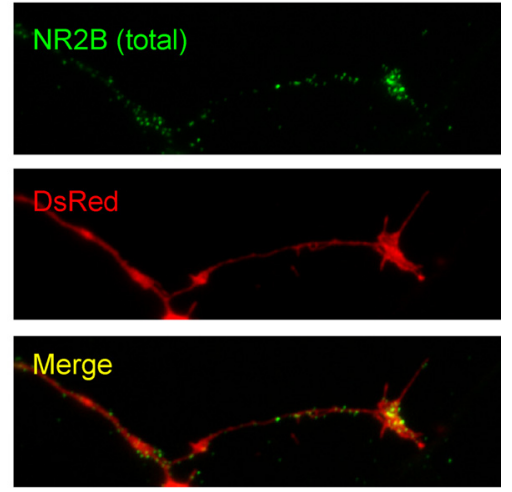

Figure 3. Transfected NR2A and NR2B is expressed on the surface of axons and growth cones. Primary hippocampal cultures

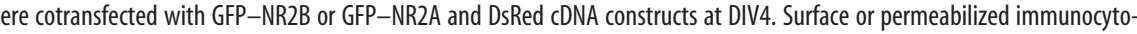
growth cones. $\boldsymbol{B}, \boldsymbol{D}$, Total/permeabilized staining of GFP-NR2A and GFP-NR2B show substantial amounts of NMDAR subunits at

(DsRed) cDNA at DIV4. Surface or permeabilized immunocytochemistry was performed $48 \mathrm{~h}$ later using a GFP antibody to examine the localization of the transfected subunits (Fig. 3). The fluorescence intensity of the transfected GFP-NR2A and NR2B was extremely low in neurites and only readily detectable with enhancement. Therefore, we performed GFP surface immunolabeling with these transfected GFP-NR2A and GFP-NR2B proteins. Our results show that exogenous GFP-NR2A and GFPNR2B are present on the surface (Fig. $3 A, C$ ) and intracellularly (Fig. $3 B, D$ ) in discrete, punctate locations along the entire cell, including the axon shaft, the lamellipodial structure, and the filopodial tips of the growth cone. Both NR2B and NR2A show similar results, indicating that they may use similar mechanisms to traffic to the growth cones. Because of a lack of highly specific antibodies, reliable labeling of endogenous NR2A and NR2B was not obtainable. These results indicate that NMDARs are present in, and expressed on the surface of, axon shafts and axonal growth cones of young primary hippocampal cultures.

\section{NMDARs are functional at axonal growth cones}

Our experiments thus far have established that NMDARs are present at axons and growth cones of DIV3-DIV6 primary hippocampal neurons. Next, we investigated whether these NMDARs are functional. Low-density primary hippocampal neurons were cultured such that individual cells were isolated and not in contact with other neurons or glia. At DIV3-DIV6, the neurons were examined by whole-cell voltage-clamp technique $(-70 \mathrm{mV}$ holding potential). NMDA $(200 \mu \mathrm{M})$ was then locally 


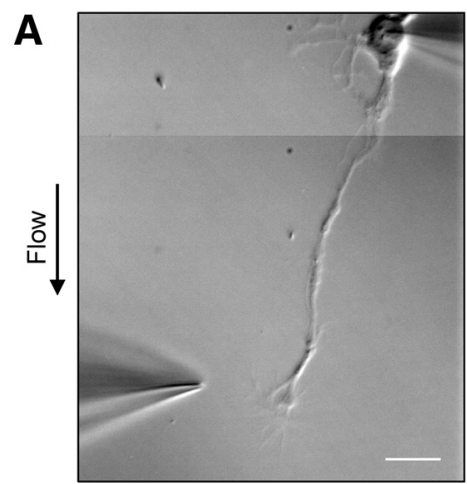

B

C

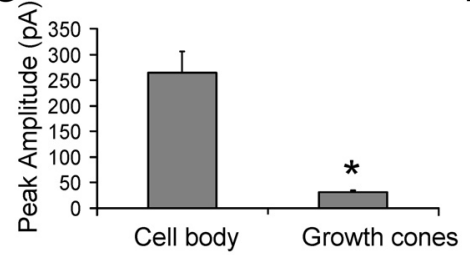

E

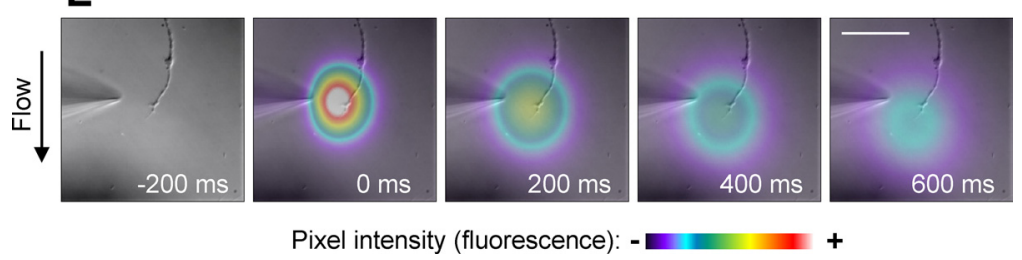

Figure 4. Functional NMDARs are present at axonal growth cones. DIV3-DIV6 primary hippocampal cultures were whole-cell voltage clamped at the cell body, and NMDA $(200 \mu \mathrm{m})$ was applied to the growth cone or cell body by pressure application ( $100 \mathrm{~ms}$, at 4-6 psi). $\boldsymbol{A}$, A composite differential interference contrast (DIC) image of a representative cell from which the currents were recorded in response to NMDA application. The position of the application pipette is shown. Scale bar, $20 \mu \mathrm{m}$. Electrophysiological recordings were performed in the presence of TTX $(1 \mu \mathrm{M})$. To test the specificity of the NMDA-mediated response at growth cones (GC), $100 \mu \mathrm{m}$ DL-APV was added to the recording solution and NMDA was applied to the growth cone ( $\boldsymbol{B}$, bottom trace). Currents observed after NMDA application were eliminated after application of DL-APV. C, Average peak amplitudes for NMDA currents recorded after application of NMDA at the cell body and growth cones were $265 \pm 40.9$ and $31 \pm 3.4 \mathrm{pA}$, respectively $(n=10)$. $D$, Average charge (in femtocoulombs) of currents elicited by applying NMDA to growth cones, before and after APV application (14.4 \pm 5.1 and $0.038 \pm 0.5 \mathrm{fC}$, respectively) $(n=10)$. Values shown are mean \pm SEM and analyzed by unpaired Student's $t$ test, ${ }^{*} p<0.05$. $E$, To examine the area of the pressure application cloud, a recording electrode was loaded with Alexa Fluor 488 and applied into the solution. Time-lapse frames are in $200 \mathrm{~ms}$ intervals. Fluorescent signals of the application were pseudocolored based on pixel intensity. The fluorescent images were digitally overlaid onto a DIC image of the experimental system for visualization purposes. Scale bar, $50 \mu \mathrm{m}$.

applied to the axonal growth cone by pressure application (4-6 psi) for $100 \mathrm{~ms}$. Recordings were performed in a HEPES-based, magnesium-free extracellular solution containing $0.2 \mathrm{mM} \mathrm{CaCl}_{2}$. Our cesium-based internal recording solution contained $5 \mathrm{~mm}$ EGTA to avoid calcium-mediated excitotoxicity. To restrict the NMDA application to the growth cone, only neurons that were oriented with the cell body positioned upstream of the perfusion flow, and at least $100 \mu \mathrm{m}$ from the growth cone, were chosen for analysis (Fig. 4A). The application pipettes had resistances ranging from 4 to $6 \mathrm{M} \Omega$ and were positioned $10-20 \mu \mathrm{m}$ from the growth cone. This application system allows us to specifically target the NMDA application to the growth cones but avoid the dendrites and cell body, although it is likely that regions of the distal axon were also within the area of the application (Fig. 4E). For each cell examined, NMDA was applied onto the cell body as a control. The pipette was then repositioned, and NMDA was applied to the growth cone for three trials (once per minute). Representative traces from a single cell (application at the cell body, growth cone, and growth cone in the presence of APV) are shown in Figure 4B. Perfusion of extracellular solution contain- ing the NMDAR antagonist DL-APV (100 $\mu \mathrm{M}$ ) eliminated the currents induced by NMDA application to the growth cone, indicating that this response is mediated by NMDARs and not attributable to a mechanical artifact. In addition, these experiments were performed in the presence of $1 \mu \mathrm{M}$ tetrodotoxin (TTX) to improve voltage clamp and prevent spontaneous action potentials or subthreshold depolarization. Application of NMDA to the growth cone elicited a highly reproducible current with an average peak amplitude of $31 \pm 3.4 \mathrm{pA}$ compared with $265 \pm 40.9 \mathrm{pA}$ at the cell body $(n=10)$ (Fig. 4C). Based on a single-channel NMDA receptor conductance of $50 \mathrm{pS}$ (Stern et al., 1992), currents evoked by application of NMDA to the growth cone may represent the opening of only $\sim 10$ channels. Therefore, to quantify the effects of APV, we integrated the traces to measure charge. NMDA application to the growth cone was reduced from $14.4 \pm$ $5.1 \mathrm{fC}$ under control conditions to $0.038 \pm 0.5 \mathrm{fC}$ in the presence of APV (Fig. 4D). The APV-sensitive currents evoked by local application of NMDA demonstrate that NMDARs on axonal growth cones are functional.

\section{NMDAR activation at growth cones promotes localized calcium influx}

NMDARs are calcium-permeable ion channels. Therefore, to obtain additional evidence for the localization of functional NMDARs at growth cones, we used fluorescence microscopy to image calcium transients in growth cones of DIV3-DIV6 primary hippocampal neurons. We began by performing a qualitative analysis of NMDA-mediated calcium influx at growth cones using the high-affinity cellpermeable fluorescent calcium indicator Fluo-4 AM. Neurons were loaded with Fluo-4 AM, and NMDA was applied to the growth cone by pressure application. Highly dynamic calcium transients, visualized using fluorescent microscopy, appeared at various regions of the growth cone and propagated down the axon shaft (Fig. 5B). For each cell examined, the addition of 100 $\mu \mathrm{M}$ DL-APV to the extracellular solution prevented these calcium transients (Fig. 5C). This response was NMDAR specific because the subsequent removal of the DL-APV-containing ACSF led to a recovery of the calcium transients (Fig. 5D). It is unlikely that propagation of the transients was attributable to diffusion, because calcium ions diffuse quite slowly in the cytoplasm with a coefficient of $\sim 10 \mu \mathrm{m}^{2} \mathrm{~s}^{-1}$ (al-Baldawi and Abercrombie, 1995; Murthy et al., 2000). However, release of calcium from internal stores mediated by $\mathrm{IP}_{3}$ and ryanodine receptors can produce localized bursts of high levels of cytoplasmic calcium (Zheng and Poo, 2007). To address the possibility that NMDAR-mediated depolarization and activation of VSCCs or calcium-induced calcium release from intracellular stores may contribute to these transients, we isolated the NMDA component through the use of 
pharmacological compounds. We loaded DIV3-DIV6 neurons with the calcium indicator Fluo-5F AM (a lower-affinity indicator than Fluo-4 with improved dynamic range), and the cells were then treated by bath application, with a combination of blockers. An example of the application system is shown in Figure 6A. To prevent potential contributions from VSCCs to the calcium transients, a combination of blockers, including $0.1 \mu \mathrm{M}$ $\omega$-conotoxin MVIIC, $0.03 \mu \mathrm{M}$ SNX-482, 20 $\mu \mathrm{M}$ nimodipine, and $10 \mu \mathrm{M}$ mibefredil, was added to the extracellular solution. These compounds block VSCCs $\mathrm{CaV}_{2.1 / 2.2}$ (P/Qand $\mathrm{N}$-type), $\mathrm{CaV}_{2.3}$ (R-type), $\mathrm{CaV}_{1.2 / 1.3}$ (L-type), and $\mathrm{CaV}_{3}$ (T-type) classes of VSCCs, respectively. TTX $(1 \mu \mathrm{M})$ was also added to the solution to block voltagesensitive sodium channels and spontaneous action potentials. To block the replenishment of intracellular calcium stores, $20 \mu \mathrm{M}$ CPA was added to the extracellular solution. In the presence of these blockers, NMDA application to growth cones still caused local calcium transients at growth cones with an average peak increase in fluorescence intensity $(\Delta F / F$, $n=15$ ) of $62.7 \pm 20.1 \%$ (Fig. $6 B$ ). As expected, bath application of APV blocked the transients $(n=15)$ (Fig. $6 B)$. To examine the spatial distribution of the calcium transients, the acquired images were analyzed and average $\Delta F / F$ images were generated using MetaMorph. The fluorescent calcium transient extended throughout the entire growth cone structure, although there were often areas of increased intensity occurring at discrete locations on the growth cone (Fig. 6C). These areas in which calcium reached higher levels may represent regions in which NMDARs are present at greater density. These results demonstrate that NMDARs at axonal growth cones are functional and mediate localized influx of calcium.

\section{NMDAR localization later in development}

Our studies thus far have demonstrated that NMDARs are present and functional at axons and axonal growth cones of DIV3DIV6 hippocampal neurons. A growing body of literature has suggested a role for presynaptic NMDARs in modulating synaptic function and plasticity (Corlew et al., 2008). However, the function of the NMDARs throughout development, particularly during the period between neurite outgrowth and synapse formation, remains unclear. To examine the presence of NMDARs at axons later in development, DIV14 hippocampal neurons were cotransfected with DsRed and YFP-NR1-1, GFP-NR2B, or GFPNR2A and immunostained for YFP or GFP on DIV16. Transfected NMDAR subunits were present in the cell body and dendrites of these older cultures, but their expression was greatly reduced at distal axonal shafts and arborizations (Fig. 7), indicat- ing that the expression and trafficking of NMDAR subunits at axons is developmentally regulated.

\section{Discussion}

Functions of NMDARs at growth cones

Our results demonstrate that NMDARs are present and functional at axonal growth cones of young primary hippocampal neurons. The localization of NMDARs was elucidated through staining of native and transfected NMDAR subunits at both light and electron microscopic levels. Our electrophysiological recordings and calcium imaging experiments demonstrate functional evidence of NMDAR activity at growth cones of hippocampal neurons. This suggests that NMDARs may mediate facets of calcium signaling that are known to be critical components of growth cone activity, including growth cone motility, turning, and activation of intracellular signaling pathways. 


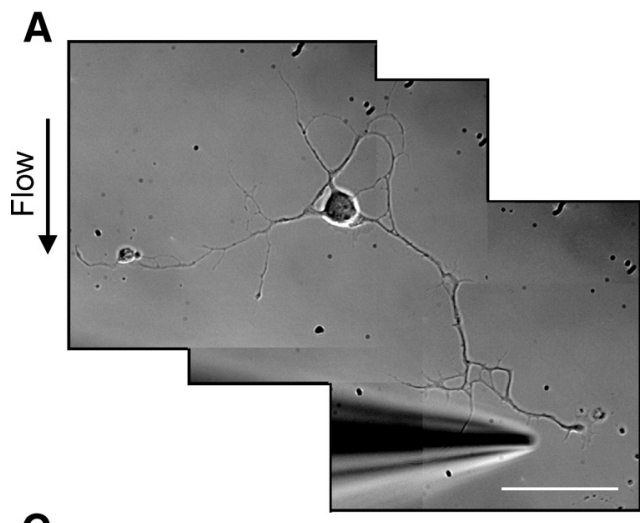

C

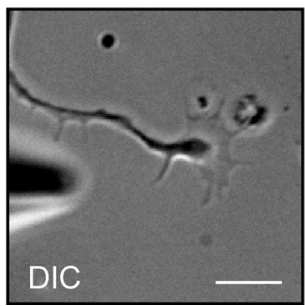

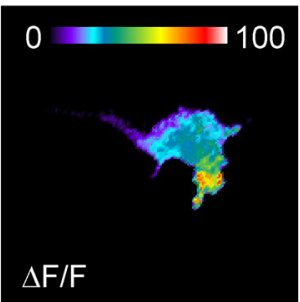

B
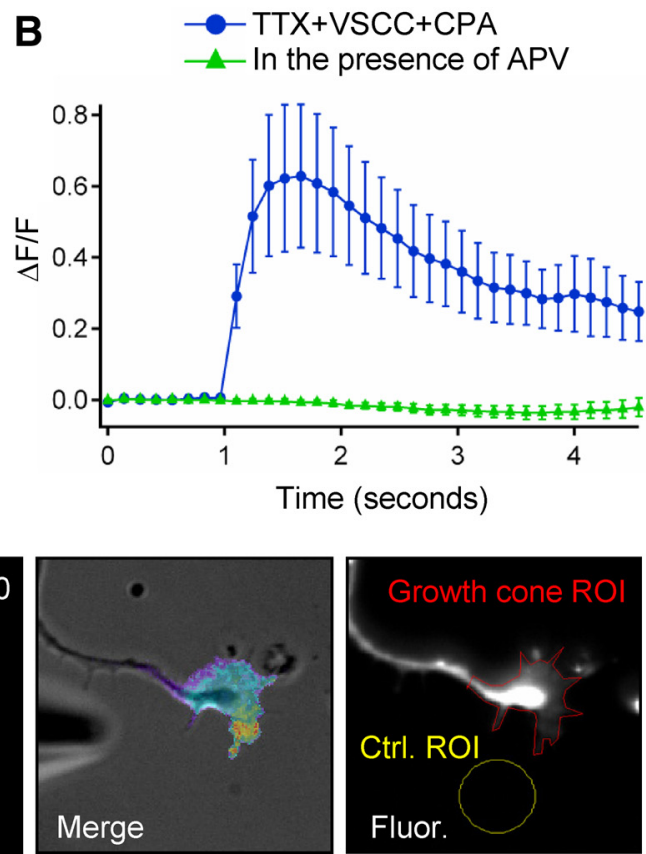

Figure 6. NMDARs mediate localized calcium influx at axonal growth cones. DIV3-DIV6 neurons were loaded with Fluo-5F AM fluorescent calcium indicator. $A$, Representative DIC image of the experimental system. Scale bar, $50 \mu \mathrm{m} . \boldsymbol{B}, \Delta F / F$ analysis reveals an increase in fluorescence (calcium transients) at the growth cone after local application of $200 \mu \mathrm{m}$ NMDA (blue). To isolate the NMDA-mediated component, experiments were performed in the presence of $1 \mu \mathrm{M} \mathrm{TTX,VSCC} \mathrm{blockers} \mathrm{(} 0.1 \mu \mathrm{m} \omega$-conotoxin MVIIC, $0.03 \mu \mathrm{m}$ SNX-482, $20 \mu \mathrm{m}$ nimodipine, and $10 \mu \mathrm{m}$ mibefredil), and $20 \mu \mathrm{M}$ CPA (which blocks the replenishment of intracellular calcium stores). Application of $100 \mu \mathrm{m} \mathrm{APV} \mathrm{to} \mathrm{the} \mathrm{extracellular} \mathrm{solution} \mathrm{blocked} \mathrm{NMDA-mediated} \mathrm{calcium} \mathrm{transients} \mathrm{(green).} \mathrm{C,} \triangle F / F$ image analysis indicates the spatial distribution of calcium transients within the growth cone. Scale bar, $10 \mu \mathrm{m}$. The far right panel shows representative growth cone and background (Ctrl.) ROIs chosen for $\Delta F / F$ measurements performed in $\boldsymbol{B}$.
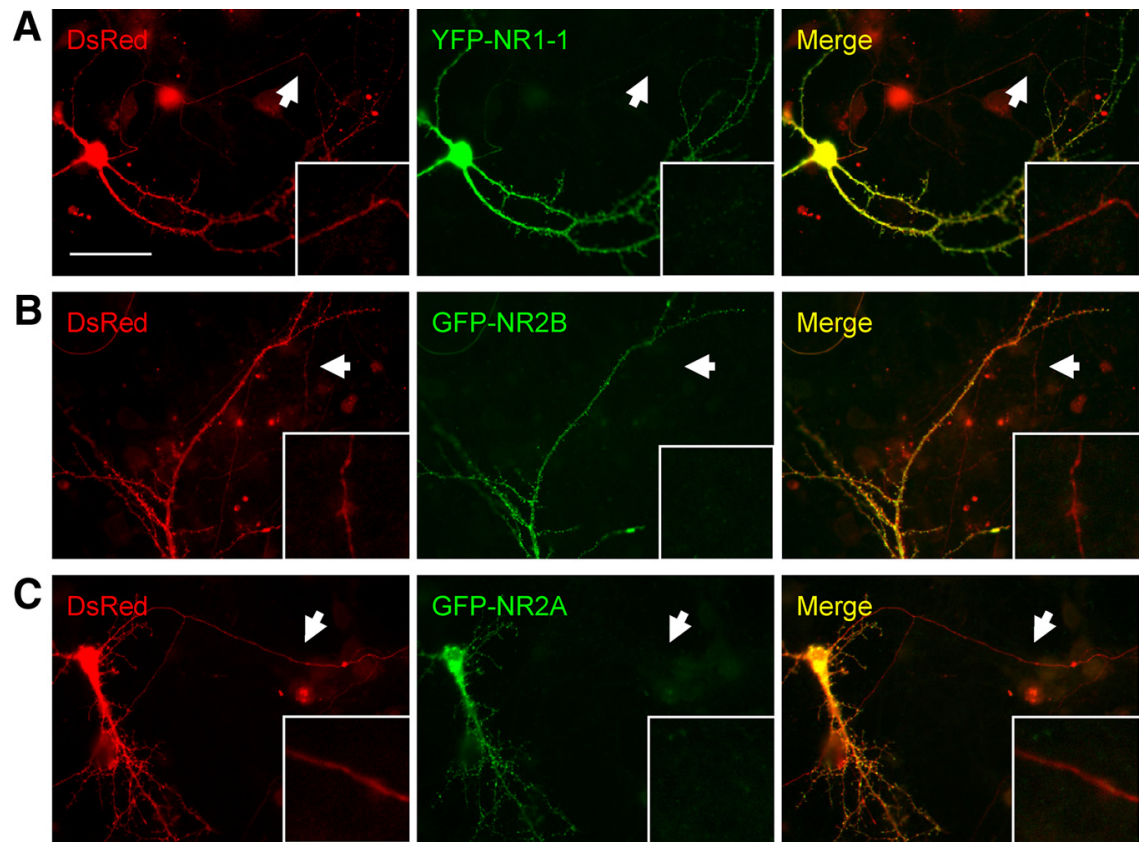

Figure 7. Expression of transfected NMDARs at distal axons is greatly reduced later in development. Primary hippocampal cultures were cotransfected with GFP-NR2B or GFP-NR2A and DsRed CDNA constructs at DIV14. Immunocytochemistry was performed $48 \mathrm{~h}$ later using GFP and RFP primary antibodies. $A-C$, Transfected YFP-NR1-1, GFP-NRB, and GFP-NR2A are expressed at the cell body and in dendrites, but expression at distal axonal processes (arrows) is greatly reduced. Scale bar, $50 \mu \mathrm{m}$.

Numerous signaling molecules implicated in growth cone functions have associations with NMDARs. For example, NMDARs have been implicated in the activity of Rho GTPases (including Cdc42, Rac, and Rho), which have essential roles in developmental mechanisms, including neurite outgrowth, neuronal migration, axon guid- ance, and growth cone motility (Luo, 2000; Dickson, 2001; Fukata et al., 2003). In vivo time-lapse imaging indicates that NMDAR activity is required for Rho GTPasemediated dendritic growth in Xenopus laevis tadpoles (Sin et al., 2002). MAGUKs directly associate with various effectors of Rho GTPases (such as SynGAP, kalirin-7, and citron) potentially providing direct links to NMDAR activity (Chen et al., 1998; Kim et al., 1998; Furuyashiki et al., 1999; Zhang et al., 1999; Penzes et al., 2001). NMDARs also interact (either directly or indirectly) with numerous families of cellular adhesion molecules (CAMs) to mediate synaptic activity and plasticity, including cadherins and neuroligins (Huntley et al., 2002; Craig and Kang, 2007; Wenthold et al., 2008). It is possible that similar CAMs interact with NMDARs in the growth cones.

Although the mechanisms that activate NMDARs at growth cones in vivo are not known, our results suggest that endogenous glutamate could serve as the agonist for growth cone-resident NMDARs. Spontaneous firing of developing neurons may be sufficient to depolarize the cell and release the voltage-dependent magnesium block of NMDARs. Therefore, growth cone dynamics may be regulated by an interaction between localized NMDAR-mediated signals and VGCCs, which have been implicated previously in various growth-cone-mediated dynamics (Zheng and Poo, 2007; Nishiyama et al., 2008). 


\section{Transient targeting of NMDARs to axons and growth cones} We demonstrated that the targeting of NMDARs to axons is specific but transient, suggesting that NMDARs undergo targeted trafficking and/or endocytosis to achieve developmental polarization. Our data indicate that NMDARs are located at axons early, but not late, in postnatal development. These results are not without precedent. Previously, Herkert et al. (1998) reported that native NR2B is present at axons and growth cones in young hippocampal neurons at DIV6 but is absent from axons at DIV20 (Herkert et al., 1998). Similarly, a report using hippocampal neurons indicates that NR2B is present throughout the cell at DIV3 but is restricted to somatodendritic sites by DIV5 and exhibits clustering with postsynaptic proteins at DIV10 (Song et al., 2009). Ehlers et al. (1998) found native NR1 at axons and growth cones of DIV10 hippocampal neurons. In our study using DIV16 neurons, the transfected YFP-NR1-1, GFP-NR2A, and GFPNR2B often showed several discrete puncta extending from the soma into the axon hillock and the proximal axon, with decreasing expression along the axon more distally.

The selective localization of polarized synaptic proteins can be achieved through several mechanisms, including (1) selective targeting of proteins to axonal or dendritic surfaces, (2) nonspecific targeting, followed by selective retention/removal from axons or dendrites, and (3) transcytosis from dendritic to axonal compartments (Sampo et al., 2003; Wisco et al., 2003; Yap et al., 2008). For example, VAMP2 traffics to the surface of both axons and dendrites early in development but is preferentially endocytosed from the dendritic membrane as a result of an intracellular motif (Sampo et al., 2003). Wisco et al. (2003) and Yap et al. (2008) showed that neuron-glia cell adhesion molecule (NgCAM) traffics to dendrites and subsequently undergoes translocation to axons via endosomal recycling vesicles, whereas Sampo et al. (2003) suggest that axonal targeting of $\mathrm{NgCAM}$ is directly related to the presence of its extracellular FN3 domains. KIF5 (a member of the kinesin superfamily) is selectively targeted to axons (Nakata and Hirokawa, 2003), whereas KIF17 has been implicated in the dendritic targeting of NR2B via PDZ-associated interactions (Setou et al., 2000; Guillaud et al., 2003). The mechanism underlying the developmental shift in NMDAR polarization is not well understood, although a recent study indicates that the establishment of an ankyrin G- and F-actin-dependent cytoskeletal filter in the axon initial segment (AIS) selectively excludes KIF17mediated axonal NR2B trafficking (Song et al., 2009). Passage through this filter is dependent on molecular motors, and disruption of F-actin removes such barriers (Winckler et al., 1999), thereby allowing the molecules to pass through the AIS. However, KIF5-mediated transport contributes to only a portion of NMDAR trafficking (Guillaud et al., 2003). This trafficking likely involves multiple mechanisms and protein associations, working in concert to mediate this highly regulated and intricate process (Wenthold et al., 2008).

There are significant changes in NMDAR subunit expression throughout development. As development progresses, NR2A levels in the forebrain gradually increase whereas NR2B levels decline (Sans et al., 2000). Additionally, the NR2D subunit is transiently expressed in hippocampus and has been implicated in presynaptic activity (Mameli et al., 2005). Our results suggest that changes in NMDAR subunit composition may contribute to regulation of developmental changes in NMDAR localization. Future studies are required to help establish the mechanisms by which NMDA receptors achieve selective polarization in axons and dendrites throughout development.

\section{The relationship between NMDARs at axonal growth cones and presynaptic NMDARs}

NMDARs are classically described as postsynaptic receptors. However, discussion and debate over the presence and function of presynaptic NMDARs has grown in recent years (Petralia et al., 1994; Aoki, 1997; Fiszman et al., 2005; Jourdain et al., 2007; Brasier and Feldman, 2008; Christie and Jahr, 2008; Corlew et al., 2008; Bidoret et al., 2009; Christie and Jahr, 2009; McGuinness et al., 2010). A number of studies show direct evidence for presynaptic NMDARs. For example, single-channel NMDA currents have been recorded from presynaptic terminals of cerebellar basket cells (Fiszman et al., 2005), and NR1 has been found at presynaptic terminals through electron microscopy (Jourdain et al., 2007; McGuinness et al., 2010). Presynaptic NMDARs have been shown to facilitate transmitter release at hippocampal Schaffer collateral boutons (McGuinness et al., 2010). However, other studies have demonstrated that effects of NMDA receptors on presynaptic calcium influx are mediated by activation of somatic or dendritic NMDARs (Christie and Jahr, 2008, 2009). The involvement of NMDARs in mechanisms of presynaptic activity is complex, and caution must be exercised in assigning a direct presynaptic role for NMDA receptors. We find that NMDAR expression dramatically decreases in axons during development, but these observations do not preclude the presence of presynaptic NMDARs. Although the functional roles of NMDARs in growth cones and presynaptic terminals are likely distinct, similar targeting mechanisms could regulate both early targeting of NMDA receptors to growth cones and later transport of NMDARs to presynaptic terminals. Additional studies will be required to characterize NMDA receptor expression during the developmental transition from growth cones to synapses.

\section{References}

al-Baldawi NF, Abercrombie RF (1995) Calcium diffusion coefficient in Myxicola axoplasm. Cell Calcium 17:422-430.

Aoki C (1997) Postnatal changes in the laminar and subcellular distribution of NMDA-R1 subunits in the cat visual cortex as revealed by immunoelectron microscopy. Brain Res Dev Brain Res 98:41-59.

Behar TN, Scott CA, Greene CL, Wen X, Smith SV, Maric D, Liu QY, Colton CA, Barker JL (1999) Glutamate acting at NMDA receptors stimulates embryonic cortical neuronal migration. J Neurosci 19:4449-4461.

Bidoret C, Ayon A, Barbour B, Casado M (2009) Presynaptic NR2Acontaining NMDA receptors implement a high-pass filter synaptic plasticity rule. Proc Natl Acad Sci U S A 106:14126-14131.

Brasier DJ, Feldman DE (2008) Synapse-specific expression of functional presynaptic NMDA receptors in rat somatosensory cortex. J Neurosci 28:2199-2211.

Brewer GJ, Cotman CW (1989) NMDA receptor regulation of neuronal morphology in cultured hippocampal neurons. Neurosci Lett 99:268-273.

Chen HJ, Rojas-Soto M, Oguni A, Kennedy MB (1998) A synaptic RasGTPase activating protein (p135 SynGAP) inhibited by CaM kinase II. Neuron 20:895-904.

Christie JM, Jahr CE (2008) Dendritic NMDA receptors activate axonal calcium channels. Neuron 60:298-307.

Christie JM, Jahr CE (2009) Selective expression of ligand-gated ion channels in L5 pyramidal cell axons. J Neurosci 29:11441-11450.

Corlew R, Brasier DJ, Feldman DE, Philpot BD (2008) Presynaptic NMDA receptors: newly appreciated roles in cortical synaptic function and plasticity. Neuroscientist 14:609-625.

Craig AM, Kang Y (2007) Neurexin-neuroligin signaling in synapse development. Curr Opin Neurobiol 17:43-52.

Dickson BJ (2001) Rho GTPases in growth cone guidance. Curr Opin Neurobiol 11:103-110.

Ehlers MD, Fung ET, O’Brien RJ, Huganir RL (1998) Splice variant-specific interaction of the NMDA receptor subunit NR1 with neuronal intermediate filaments. J Neurosci 18:720-730.

Fiszman ML, Barberis A, Lu C, Fu Z, Erdélyi F, Szabó G, Vicini S (2005) 
NMDA receptors increase the size of GABAergic terminals and enhance GABA release. J Neurosci 25:2024-2031.

Forrest D, Yuzaki M, Soares HD, Ng L, Luk DC, Sheng M, Stewart CL, Morgan JI, Connor JA, Curran T (1994) Targeted disruption of NMDA receptor 1 gene abolishes NMDA response and results in neonatal death. Neuron 13:325-338.

Fukata M, Nakagawa M, Kaibuchi K (2003) Roles of Rho-family GTPases in cell polarisation and directional migration. Curr Opin Cell Biol 15: 590-597.

Furuyashiki T, Fujisawa K, Fujita A, Madaule P, Uchino S, Mishina M, Bito H, Narumiya S (1999) Citron, a Rho-target, interacts with PSD-95/SAP-90 at glutamatergic synapses in the thalamus. J Neurosci 19:109-118.

Guillaud L, Setou M, Hirokawa N (2003) KIF17 dynamics and regulation of NR2B trafficking in hippocampal neurons. J Neurosci 23:131-140.

Henley J, Poo MM (2004) Guiding neuronal growth cones using $\mathrm{Ca}^{2+}$ signals. Trends Cell Biol 14:320-330.

Herkert M, Röttger S, Becker CM (1998) The NMDA receptor subunit NR2B of neonatal rat brain: complex formation and enrichment in axonal growth cones. Eur J Neurosci 10:1553-1562.

Huntley GW, Gil O, Bozdagi O (2002) The cadherin family of cell adhesion molecules: multiple roles in synaptic plasticity. Neuroscientist 8:221-233.

Jourdain P, Bergersen LH, Bhaukaurally K, Bezzi P, Santello M, Domercq M, Matute C, Tonello F, Gundersen V, Volterra A (2007) Glutamate exocytosis from astrocytes controls synaptic strength. Nat Neurosci 10: 331-339.

Kamiguchi H, Lemmon V (2000) Recycling of the cell adhesion molecule L1 in axonal growth cones. J Neurosci 20:3676-3686.

Kim JH, Liao D, Lau LF, Huganir RL (1998) SynGAP: a synaptic RasGAP that associates with the PSD-95/SAP90 protein family. Neuron 20: 683-691.

Komuro H, Rakic P (1993) Modulation of neuronal migration by NMDA receptors. Science 260:95-97.

Kumada T, Komuro H (2004) Completion of neuronal migration regulated by loss of $\mathrm{Ca}^{2+}$ transients. Proc Natl Acad Sci U S A 101:8479-8484.

Luo L (2000) Rho GTPases in neuronal morphogenesis. Nat Rev Neurosci 1:173-180.

Mameli M, Carta M, Partridge LD, Valenzuela CF (2005) Neurosteroidinduced plasticity of immature synapses via retrograde modulation of presynaptic NMDA receptors. J Neurosci 25:2285-2294.

McGuinness L, Taylor C, Taylor RD, Yau C, Langenhan T, Hart ML, Christian H, Tynan PW, Donnelly P, Emptage NJ (2010) Presynaptic NMDARs in the hippocampus facilitate transmitter release at theta frequency. Neuron 68:1109-1127.

Murthy VN, Sejnowski TJ, Stevens CF (2000) Dynamics of dendritic calcium transients evoked by quantal release at excitatory hippocampal synapses. Proc Natl Acad Sci U S A 97:901-906.

Nakata T, Hirokawa N (2003) Microtubules provide directional cues for polarized axonal transport through interaction with kinesin motor head. J Cell Biol 162:1045-1055.

Nishiyama M, von Schimmelmann MJ, Togashi K, Findley WM, Hong K (2008) Membrane potential shifts caused by diffusible guidance signals direct growth-cone turning. Nat Neurosci 11:762-771.

Pearce IA, Cambray-Deakin MA, Burgoyne RD (1987) Glutamate acting on NMDA receptors stimulates neurite outgrowth from cerebellar granule cells. FEBS Lett 223:143-147.

Penzes P, Johnson RC, Sattler R, Zhang X, Huganir RL, Kambampati V, Mains RE, Eipper BA (2001) The neuronal Rho-GEF Kalirin-7 interacts with PDZ domain-containing proteins and regulates dendritic morphogenesis. Neuron 29:229-242.

Petralia RS, Wenthold RJ (1999) Immunocytochemistry of NMDA receptors. Methods Mol Biol 128:73-92.

Petralia RS, Yao PJ (2007) AP180 and CALM in the developing hippocampus: expression at the nascent synapse and localization to trafficking organelles. J Comp Neurol 504:314-327.
Petralia RS, Yokotani N, Wenthold RJ (1994) Light and electron microscope distribution of the NMDA receptor subunit NMDAR1 in the rat nervous system using a selective anti-peptide antibody. J Neurosci 14:667-696.

Petralia RS, Wang YX, Hua F, Yi Z, Zhou A, Ge L, Stephenson FA, Wenthold RJ (2010) Organization of NMDA receptors at extrasynaptic locations. Neuroscience 167:68-87.

Rashid NA, Cambray-Deakin MA (1992) N-methyl-D-aspartate effects on the growth, morphology and cytoskeleton of individual neurons in vitro. Brain Res Dev Brain Res 67:301-308.

Rees RP, Bunge MB, Bunge RP (1976) Morphological changes in the neuritic growth cone and target neuron during synaptic junction development in culture. J Cell Biol 68:240-263.

Sampo B, Kaech S, Kunz S, Banker G (2003) Two distinct mechanisms target membrane proteins to the axonal surface. Neuron 37:611-624.

Sans N, Petralia RS, Wang YX, Blahos J 2nd, Hell JW, Wenthold RJ (2000) A developmental change in NMDA receptor-associated proteins at hippocampal synapses. J Neurosci 20:1260-1271.

Schmitz Y, Luccarelli J, Kim M, Wang M, Sulzer D (2009) Glutamate controls growth rate and branching of dopaminergic axons. J Neurosci 29:11973-11981.

Setou M, Nakagawa T, Seog DH, Hirokawa N (2000) Kinesin superfamily motor protein KIF17 and mLin-10 in NMDA receptor-containing vesicle transport. Science 288:1796-1802.

Sin WC, Haas K, Ruthazer ES, Cline HT (2002) Dendrite growth increased by visual activity requires NMDA receptor and Rho GTPases. Nature 419:475-480

Song AH, Wang D, Chen G, Li Y, Luo J, Duan S, Poo MM (2009) A selective filter for cytoplasmic transport at the axon initial segment. Cell 136:1148-1160.

Stern P, Béhé P, Schoepfer R, Colquhoun D (1992) Single-channel conductances of NMDA receptors expressed from cloned cDNAs: comparison with native receptors. Proc Biol Sci 250:271-277.

Tárnok K, Czöndör K, Jelitai M, Czirók A, Schlett K (2008) NMDA receptor NR2B subunit over-expression increases cerebellar granule cell migratory activity. J Neurochem 104:818-829.

Wang PY, Seabold GK, Wenthold RJ (2008) Synaptic adhesion-like molecules (SALMs) promote neurite outgrowth. Mol Cell Neurosci 39:83-94.

Washbourne P, Liu XB, Jones EG, McAllister AK (2004) Cycling of NMDA receptors during trafficking in neurons before synapse formation. J Neurosci 24:8253-8264.

Wenthold RJ, Al-Hallaq RA, Swanwick CC, Petralia RS (2008) Molecular properties and cell biology of the NMDA receptor. In: Structural and functional organization of the synapse (Hell JW, Ehlers MD, eds), pp 317-367. New York: Springer.

Winckler B, Forscher P, Mellman I (1999) A diffusion barrier maintains distribution of membrane proteins in polarized neurons. Nature 397: 698-701.

Wisco D, Anderson ED, Chang MC, Norden C, Boiko T, Fölsch H, Winckler B (2003) Uncovering multiple axonal targeting pathways in hippocampal neurons. J Cell Biol 162:1317-1328.

Yap CC, Wisco D, Kujala P, Lasiecka ZM, Cannon JT, Chang MC, Hirling H, Klumperman J, Winckler B (2008) The somatodendritic endosomal regulator NEEP21 facilitates axonal targeting of L1/NgCAM. J Cell Biol 180:827-842.

Zhang W, Vazquez L, Apperson M, Kennedy MB (1999) Citron binds to PSD-95 at glutamatergic synapses on inhibitory neurons in the hippocampus. J Neurosci 19:96-108.

Zheng JQ, Poo MM (2007) Calcium signaling in neuronal motility. Annu Rev Cell Dev Biol 23:375-404.

Zheng JQ, Wan JJ, Poo MM (1996) Essential role of filopodia in chemotropic turning of nerve growth cone induced by a glutamate gradient. J Neurosci 16:1140-1149. 